\title{
Ergot Resistant Tetraploid Bahiagrass and Fungicide Effects on Seed Yield and Quality
}

\begin{abstract}
Esteban Rios, Department of Agronomy, University of Florida, Gainesville 32611; Ann Blount, Department of Agronomy, North Florida Research and Education Center, University of Florida, Marianna 32446; Philip Harmon, Department of Plant Pathology, University of Florida, Gainesville 32611; Cheryl Mackowiak, Department of Soil and Water Science, North Florida Research and Education Center, University of Florida, Quincy 32351; Kevin Kenworthy and Kenneth Quesenberry, Department of Agronomy, University of Florida, Gainesville 32611
\end{abstract}

Accepted for publication 24 February 2015. Published 17 April 2015.

\section{ABSTRACT}

Rios, E., Blount, A., Harmon, P., Mackowiak, C., Kenworthy, K., and Quesenberry, K. 2015. Ergot resistant tetraploid bahiagrass and fungicide effects on seed yield and quality. Plant Health Progress doi:10.1094/PHP-RS-14-0051.

Seed production is a critical component in agricultural systems based on bahiagrass and ergot has been reported to significantly reduce seed quality in tetraploid cultivars. Seed yield and quality are important traits to evaluate in the advanced breeding lines developed at the University of Florida. Resistance to ergot was assessed in seven tetraploid bahiagrass breeding lines and the cultivar Argentine. Tebuconazole and pyraclostrobin also were evaluated for managing ergot and increasing seed quality. Argentine and two tetraploid hybrids (Hyb1 and Hyb2) showed the highest levels of ergot severity and incidence. Three wild-type bahiagrass lines (WT-2, WT-4 and WT-5) performed significantly better than Argentine and could be considered resistant to ergot. Anthesis was the critical stage in relation to ergot infection, and a single application of tebuconazole at anthesis reduced ergot severity; however, neither fungicide was able to reduce ergot incidence. Tebuconazole and pyraclostrobin improved seed set, and reproductive efficiency was $2.4 \%$ higher after the application of tebuconazole. The slight increase in reproductive efficiency following fungicide application may not be economically justifiable for seed production in bahiagrass. Three advanced tetraploid breeding lines (Hyb1, WT-3, and WT-5) exhibited adequate seed production to be considered for cultivar release.

\section{INTRODUCTION}

Bahiagrass (Paspalum notatum Flügge) is a warm-season perennial grass well adapted to the southeastern United States, where it covers more than 2.4 million hectares (Burton et al. 1997 ) and is considered the foundation pasture for cow/calf production systems (Blount 2013), besides its use as a lowmaintenance turfgrass (Newman et al. 2011). Seed propagation is the primary advantage of bahiagrass over vegetatively propagated grasses; therefore, a reliable source of high-quality seed is essential to successfully establish new fields. Ergot caused by Claviceps paspali F. Stevens and J.G. Hall has been reported to reduce seed quality of certain bahiagrass cultivars, primarily tetraploid genotypes (Acuña et al. 2007; Burton 1955; Knight and Bennett 1953), limiting seed supply, increasing planting costs, and affecting stand establishment.

High seed yield and quality in bahiagrass are limited by its prolonged flowering period (Adjei et al. 2000), nonsynchronous maturity of seeds on individual racemes (Burton 1942), low seed set and germination (Acuña et al. 2009; Rebozzio et al. 2011), seed shattering (Burson et al. 1978) and ergot disease (Blount and Acuña 2009; Burton 1955; Burton and Lefebvre 1948). Management practices such as timing of defoliation and fertilization rates have been demonstrated to increase seed yield in diploid and tetraploid bahiagrass (Adjei and Mislevy 1987;

Corresponding author: Dr. Ann Blount. Email: paspalum@ufl.edu

doi:10.1094/PHP-RS-14-0051

(C) 2015 The American Phytopathological Society
Adjei et al. 1992, 2000; Gates and Burton 1998; Jank 1982). However, there is a lack of information regarding the resistance to ergot exhibited by tetraploid breeding lines and about the use of fungicides to control ergot in susceptible bahiagrass cultivars.

Ergot frequently infects grasses in the genus Paspalum in the southern United States (Alderman et al. 2004). The infection cycle begins with sexual spores (ascospores) spread by wind (Alderman 2003) or possibly insects (Brown 1916; Feldman et al. 2008). The fungus infects the pistil of the flower at the time of flowering by colonizing the styles of susceptible plants, and a few days later the content of the ovary is replaced by fungal tissue (Brown 1916). In a study conducted in bahiagrass, ergot only infected florets that were sterile, while pollinated florets developed seed and were resistant to ergot infections. The authors concluded that the incidence of ergot increased as the fertility of the plant decreased because stigmas of unfertilized ovaries remained receptive for a longer time and were more prone to infection by the ergot pathogen (Burton and Lefebvre 1948). The sign of ergot infection appears at anthesis when a sugar-rich exudate (honeydew) is produced on infected florets. The honeydew makes seed heads feel sticky, and the exudates contain the asexual spores (conidia) that are responsible for initiating secondary infections (Fig. $1 \mathrm{~A}$ and B). Disease development is correlated to environmental conditions of high humidity, cloudy days, and warm temperatures, after which the disease cycle ends by forming a mass of dark fungal tissue (sclerotium) that replaces the seed and forces the glumes apart (Fig. 1 C and D) (Brown 1916). Additionally, ergot-infected seed contains alkaloids that are poisonous to animals (Brown 1916; Villar 1984). 


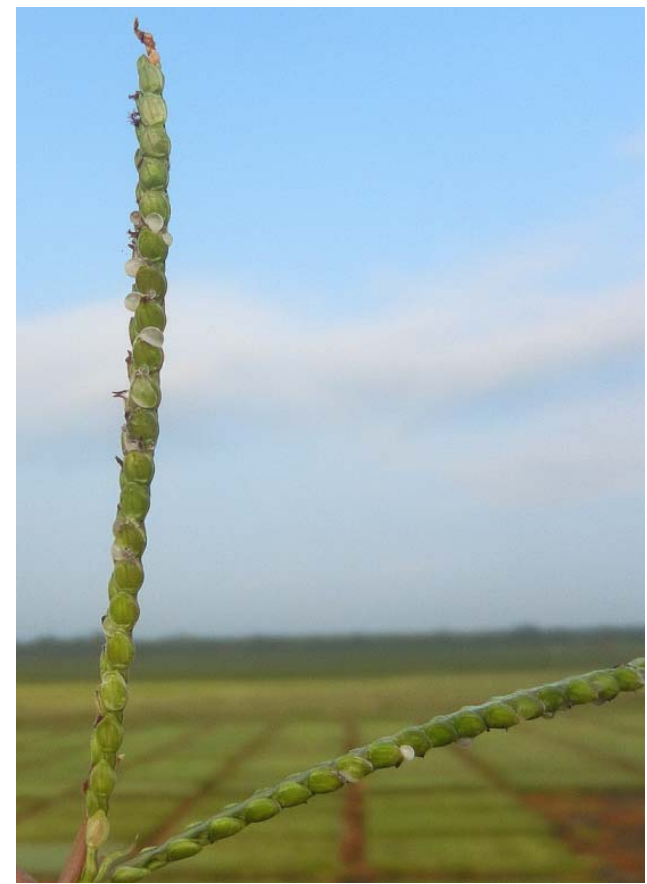

A

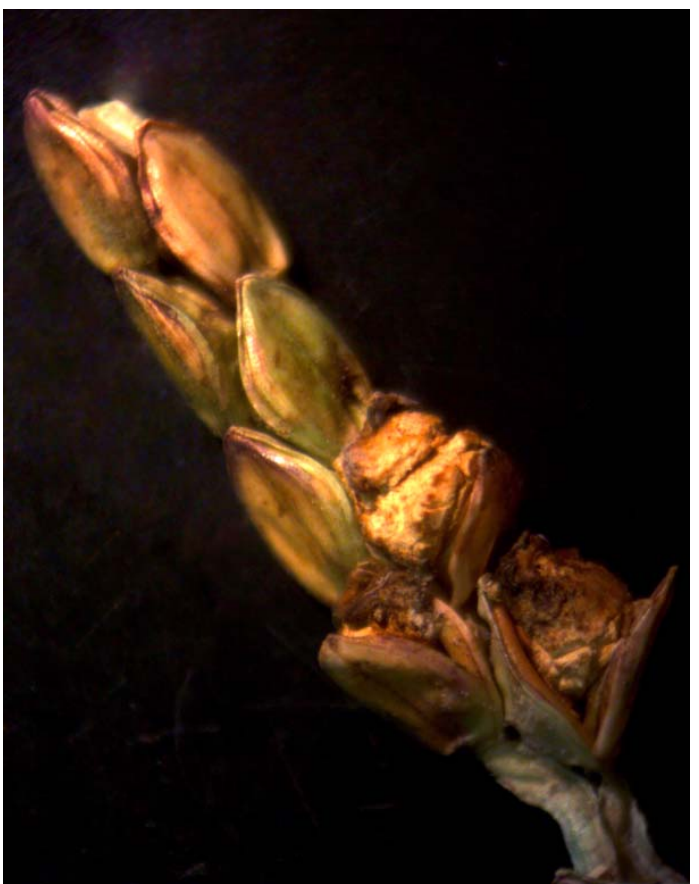

C

D

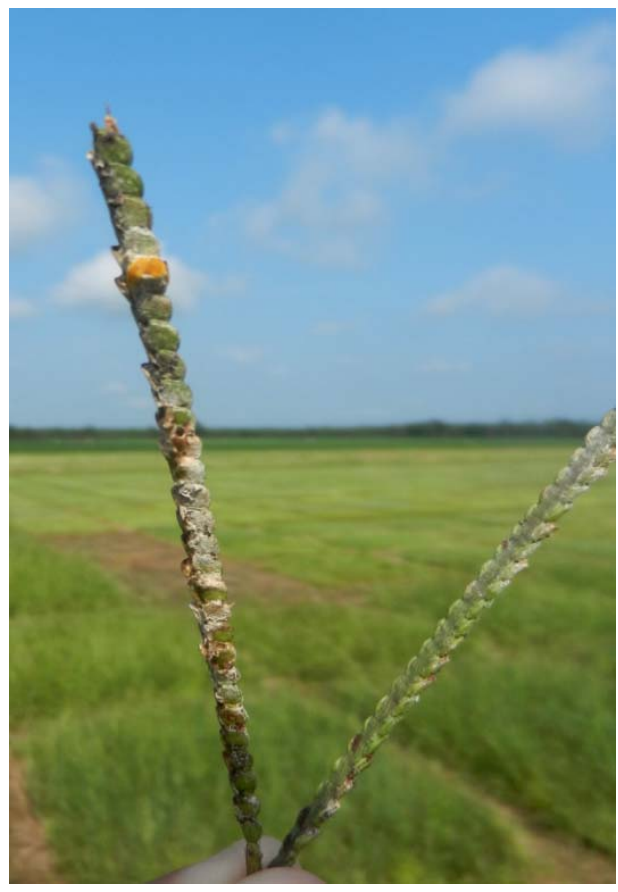

B

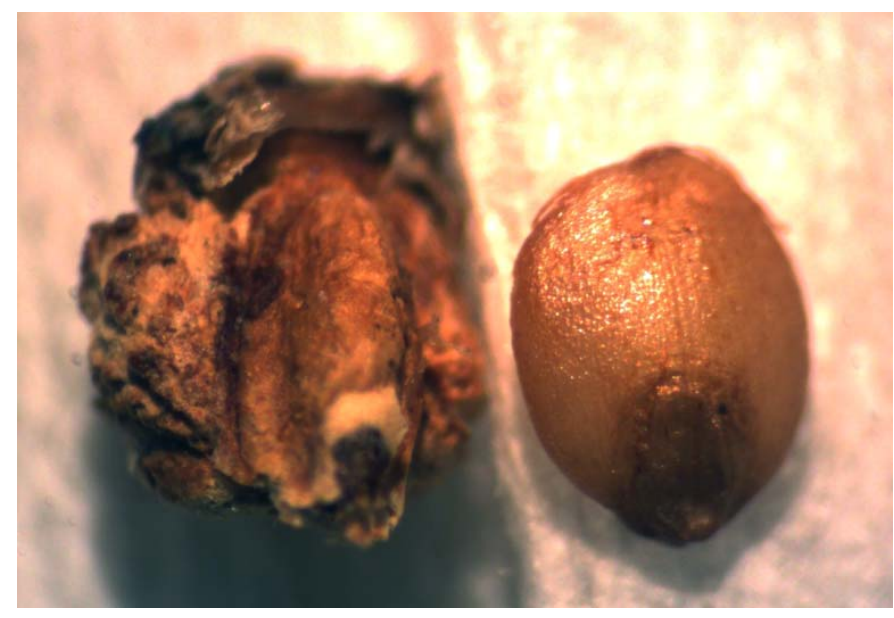

\section{FIGURE 1}

Ergot (Claviceps paspali Stevens and Hall) in 'Argentine' bahiagrass: (A) early stage of honeydew development at anthesis; (B) dried honeydew in approximate $40 \%$ of the seed head and saprophytic fungi growing in a seed head postanthesis; (C) seed head at the time of harvest with three florets whose seed was replaced by ergot (note how the fungal tissue forced the glumes apart) while the other florets were not affected by the fungus; (D) normal caryopsis fully developed, right, and caryopsis replaced by ergot, left. 
Several studies have demonstrated that properly timed fungicide applications can reduce the development of ergot in different grass species. Triazole fungicides applied at anthesis and then at 4- to 5-day intervals effectively controlled ergot in sorghum (Sorghum bicolor (L.) Moench) caused by C. africana Freder. (Ryley et al. 2003). The same authors also reported that anthesis was the most important growth stage in relation to ergot infection and that the length of the flowering period influenced disease development. Additionally, fungicide treatments significantly reduced sclerotia development under high levels of ergot infection caused by $C$. purpurea (Fr.) Tul. in Kentucky bluegrass (Poa pratensis L.), and two applications of propiconazole at $584 \mathrm{ml}$ a.i./ha produced the best results, while two applications of azoxystrobin $(877 \mathrm{ml} / \mathrm{ha})$ or tebuconazole (584 ml a.i./ha) also controlled ergot successfully. Additionally, fungicide applications significantly reduced honeydew on seed heads, and none of the fungicides affected seed weight or germination (Butler et al. 1997).

The advanced tetraploid breeding lines at the UF/IFAS bahiagrass breeding program exhibited great potential for forage production (Acuña et al. 2009) and turf applications (Rios et al. 2013a); however, seed yield and quality are important traits to evaluate prior to release of new cultivars. In addition, seed producers have reported considerable reductions in seed quality caused by ergot in the widely used cultivar Argentine. Bahiagrass grown for seed is not usually treated with fungicides to manage ergot. Two fungicides with potential preventative and curative efficacy are available for grass seed production that include tebuconazole (Folicur EW; Bayer CropScience, Research Triangle PK, NC) and pyraclostrobin (Headline EC; BASF, Research Triangle PK, NC) (Crop Data Management System 2013; Latin 2011). The forage regrowth after seed harvesting can be grazed 17 (tebuconazole) and 27 (pyraclostrobin) days after the last fungicide application, which is important because seed fields are often used for grazing after seed harvesting (Newman et al. 2011). This study was conducted in order to (i) evaluate the ergot susceptibility of novel tetraploid bahiagrass breeding lines and the efficacy of tebuconazole and pyraclostrobin for controlling ergot, and (ii) evaluate seed yield and quality in tetraploid bahiagrass after the application of fungicides.

\section{EXPERIMENTAL DESIGN AND AGRONOMIC MANAGEMENT}

The study was conducted at the Agronomy Forage Research Unit, University of Florida, Hague, FL, on a Chipley sand (Thermic, coated Aquic Quartzipsamments). The experimental design was a randomized complete block design in a split-plot arrangement with three replications. Main plots consisted of eight bahiagrass genotypes: five dwarf wild-type bahiagrass lines (WT1 to 5); two forage-type hybrids (Hyb1 and Hyb2); and the cultivar Argentine. Each main plot $(1 \mathrm{~m} \times 3 \mathrm{~m})$ was divided in 3 subplots $(1 \mathrm{~m} \times 1 \mathrm{~m})$ that received a single fungicide application of (i) tebuconazole (438 ml a.i./ha) (Folicur EW, Bayer

CropScience, Research Triangle PK, NC); (ii) pyraclostrobin (585 $\mathrm{ml}$ a.i./ha) (Headline EC, BASF, Research Triangle PK, NC); and (iii) water-treated control.

The plots were planted in 4 October 2011 using vegetatively propagated plugs and were grown to form a full stand. The experimental area was managed similarly during 2012 and 2013, when data was collected. The entire area was mowed at $10 \mathrm{~cm}$ stubble height and potassium was applied to the entire area at a rate of $60 \mathrm{~kg} \mathrm{~K} / \mathrm{ha}$, as a mixture of potassium chloride (0-0-60) and SUL-PO-MAG (0-0-22), in the spring of each year based on soil analysis. Additionally, the plots were mowed the last week of May and were immediately fertilized with $120 \mathrm{~kg} \mathrm{~N} / \mathrm{ha}$ using ammonium nitrate (34-0-0) in a single application to promote flowering and seed head development.

Flowering synchronization was achieved through mowing the plots the last week of May and then fungicide treatments were applied when all genotypes reached in average $10 \%$ anthesis using a $\mathrm{CO}_{2}$-backpack boom sprayer calibrated to deliver the products in 7.6 liters of water per $93 \mathrm{~m}^{2}$ through two Teejet flatfan nozzles. In 2012, the treatments were applied on 10 July; however, due to heavy rainfall experienced in 2013, the plots were mowed a second time at $15 \mathrm{~cm}$ stubble height on 8 July to remove old seed heads and allow the development of new inflorescences, and fungicides were applied on 25 July. A second application of fungicides was not possible in both years due to frequent and heavy rainfall experienced during both growing seasons (from 1 May to 31 July the rainfall was $970 \mathrm{~mm}$ in 2012 and $771 \mathrm{~mm}$ in 2013; Florida Automated Weather Network, University of Florida).

\section{RESPONSE VARIABLES}

All response variables were measured during the summer of 2012 and 2013 following the same protocol. Three weeks after applying the treatments, the experimental units were visually rated using a 1 to 5 scale for (i) ergot severity: $1=$ no visible honeydew or sclerotia; $2=<10 \% ; 3=11-50 \% ; 4=51-80 \%$; and $5=>80 \%$ of the seed head completely covered with honeydew and/or sclerotia (Fig. 1), and (ii) seed shattering: $1=$ no seed shattered; $2=<10 \% ; 3=11-50 \% ; 4=51-80 \%$; and $5=>80 \%$ seed shattering. Additionally, samples of inflorescences prior to reaching anthesis, at anthesis and postanthesis were sent to the UF Extension Plant Diagnostic Center for diagnosis of diseases occurring at those stages.

After visually rating the plots for ergot severity and seed shattering, mature seed heads were harvested by clipping inflorescences in the center of each plot. Harvested inflorescences were dried to approximately $10 \%$ moisture and threshed. Empty florets and other inert material were removed by blowing the seeds in an air-forced seed blower (757 South Dakota Seed Blower, Seedburo Equipment, Chicago, IL). The weight of empty and filled florets per sample was recorded, and the average weight of 100 filled and empty florets were determined for three samples. The percent seed set was calculated based on the number of florets developing a seed compared to the total number of florets.

Additionally, ergot incidence was calculated by manually counting the number of caryopses infected with ergot (florets containing a sclerotium instead of a seed) in 3 samples of 100 mature florets (Fig. $1 \mathrm{C}$ and D), and healthy seed were selected to run germination tests. Seed was scarified with concentrated sulfuric acid $\left(\mathrm{H}_{2} \mathrm{SO}_{4}, 98 \%\right.$, Sigma-Aldrich, St. Louis, MO) for a period of 5 minutes, rinsed under running water until thoroughly washed and dried using paper towels. Germination tests were carried out in petri dishes using 30 scarified seeds placed onto water-moistened filter paper, repeated three times. The plates were incubated under controlled temperature and day length in a growth chamber: $16 \mathrm{~h}$ of light at $35^{\circ} \mathrm{C}$ and $8 \mathrm{~h}$ of darkness at $22^{\circ} \mathrm{C}(8)$. The plates were kept with adequate moisture during the duration of the study. After 28 days, the number of germinated seedlings was recorded, and percent germination was determined.

Reproductive efficiency was then calculated combining seed set and germination values for each experimental unit:

Reproductive efficiency $(\%)=\left(\frac{\text { seed set } \times \text { germination }}{100}\right)$ 
Analysis of variance was performed to detect treatment effects and their interactions for each response variable. The General Linear Mixed Model (GLIMMIX) procedure (Littell et al. 2006) in SAS (SAS 9.2, Cary, NC) was used to conduct the analyses. Year, genotype, fungicide treatment, and their interactions were considered fixed factors, while blocks within each year were treated as random effects. When the year by genotype and year by treatment interactions did not significantly affect the response variables, data was combined for both years (Table 1 and 2). When effects were found to be significant, a Tukey-Kramer test was performed to simultaneously set all mean pairwise comparisons at $P<0.05$.

\section{ERGOT RESISTANT TETRAPLOID BAHIAGRASS}

The susceptibility to ergot of seven tetraploid experimental lines and Argentine bahiagrass was evaluated by assessing ergot severity and incidence under natural infestations in the field. For ergot severity, genotype $(P<0.0001)$ had a significant effect on ergot severity. The cultivar Argentine and the experimental line Hyb1 showed the highest ergot severity (Table1). Although the genotypes Hyb1 and Hyb2 share exactly the same parents (Acuña et al. 2009), the sexual female parent Fl-2-2-7 was artificially created by doubling the chromosome number of the diploid cultivar 'Tifton 9' (Quesenberry et al. 2010) and the apomictic male parent was the experimental hybrid Tifton 7, their ergot severity differed (Table 1). No information is available in the literature concerning the ergot response of these two parental genotypes and their progeny. Among the wild-type lines, honeydew and/or sclerotia were only observed on the genotypes WT-1 and WT-3, but only disease severity of the latter was significantly greater than the other wild-type genotypes (Table 1). Three wild-type tetraploid genotypes could be considered to be resistant to ergot because of the absence of ergot-infected seed during the two growing seasons (Table 1). Ergot incidence gave a more accurate estimation of the percentage of seed that was actually infected and replaced by the fungus (Fig. $1 \mathrm{C}$ and D). Ergot incidence was significantly affected by year $(P=0.003)$ and genotype $(P<0.0001)$. The average ergot incidence was slightly higher in $2013(8.8 \%)$ than in $2012(6.2 \%)$. There was a large variation among genotypes, with Argentine showing the highest percent of ergot-infected seeds, the two hybrid genotypes a medium level of infection, and only two of the wild-type lines having some infection on their seed. As expected, those wild-type lines (WT-2, WT-4, and WT-5) that showed no honeydew or sclerotia at the time of seed harvest did not have any ergotinfected seed (Table 1).

\section{THE EFFECTIVENESS OF TEBUCONAZOLE AND PYRACLOSTROBIN IN CONTROLLING ERGOT}

The fungicide effect over ergot severity and incidence was analyzed excluding the wild-type ergot resistant genotypes (WT2, WT-4, and WT-5) (Table 2). Treatment had a significant effect on ergot severity $(P=0.002)$, while it did not affect ergot incidence $(P=0.89)$. Tebuconazole significantly reduced ergot severity compared to the control, while pyraclostrobin did not significantly differ from both tebuconazole and the water-control

\begin{tabular}{|c|c|c|c|c|c|c|}
\hline \multirow[b]{2}{*}{ Genotype } & \multicolumn{6}{|c|}{$\begin{array}{l}\text { TABLE } 1 \\
\text { Mean response of seven tetraploid bahiagrass breeding lines and the cultivar Argentine to ergot } \\
\text { severity and incidence, seed shattering and seed production for data collected in } 2012 \text { and } 2013 .\end{array}$} \\
\hline & Severityw & Incidence & Shattering & sS $^{x}$ & GERM & RE \\
\hline Argentine & $3.11^{\mathrm{y}} \mathrm{a}^{\mathrm{z}}$ & $15.44 \mathrm{a}$ & $2.83 \mathrm{ab}$ & $37.1 \mathrm{bc}$ & $81.5 \mathrm{a}$ & $30.1 \mathrm{a}$ \\
\hline Hyb1 & $2.78 \mathrm{a}$ & $8.72 \mathrm{~b}$ & $2.94 \mathrm{a}$ & $30.9 \mathrm{~d}$ & $68.1 \mathrm{~b}$ & $21.1 \mathrm{bc}$ \\
\hline Hyb2 & $2.00 \mathrm{~b}$ & $10.11 b$ & $2.56 \mathrm{~b}$ & $15.3 \mathrm{e}$ & $56.5 \mathrm{c}$ & $8.60 \mathrm{~d}$ \\
\hline WT-1 & $1.17 \mathrm{c}$ & $0.94 \mathrm{c}$ & $1.00 \mathrm{c}$ & $33.1 \mathrm{dc}$ & $56.9 \mathrm{c}$ & $18.9 \mathrm{c}$ \\
\hline WT-2 & $1.00 \mathrm{c}$ & $0.00 \mathrm{c}$ & $1.00 \mathrm{c}$ & $39.2 \mathrm{ab}$ & $30.9 \mathrm{e}$ & $12.2 \mathrm{~d}$ \\
\hline WT-3 & $1.67 \mathrm{~b}$ & $2.22 \mathrm{c}$ & $1.00 \mathrm{c}$ & $42.2 \mathrm{ab}$ & $59.9 \mathrm{bc}$ & $25.2 \mathrm{~b}$ \\
\hline WT-4 & $1.00 \mathrm{c}$ & $0.00 \mathrm{c}$ & $1.00 \mathrm{c}$ & $39.7 \mathrm{ab}$ & $43.6 \mathrm{~d}$ & $17.2 \mathrm{c}$ \\
\hline WT-5 & $1.00 \mathrm{c}$ & $0.00 \mathrm{c}$ & $1.00 \mathrm{c}$ & $44.6 \mathrm{a}$ & $45.7 \mathrm{~d}$ & $20.6 \mathrm{c}$ \\
\hline
\end{tabular}

${ }^{\mathrm{w}}$ Ergot severity measured in a 1 to 5 scale $(1=$ no visible honeydew or sclerotia, $2=<10 \%, 3=11-50 \%, 4=51-80 \%$, and $5=>80 \%$ of the seed head completely covered with honeydew and/or sclerotia); Ergot incidence measured as the percent of ergot-infected seed; and seed shattering measured in a 1 to 5 scale $(1=$ no seed shattered, $2=<10 \%, 3=11-50 \%, 4=51-80 \%$, and $5=>80 \%$ seed shattering).

${ }^{\mathrm{x}} \mathrm{SS}=$ seed set $(\%), \mathrm{GERM}=$ seed germination $(\%)$, and $\mathrm{RE}=$ reproductive efficiency $(\%)$.

${ }^{y}$ Due to the absence of an interaction between year and genotype, data was combined for both years.

${ }^{\mathrm{z}}$ Means followed by the same letter are not significantly different according to Tukey-Kramer test $(\alpha=0.05)$.

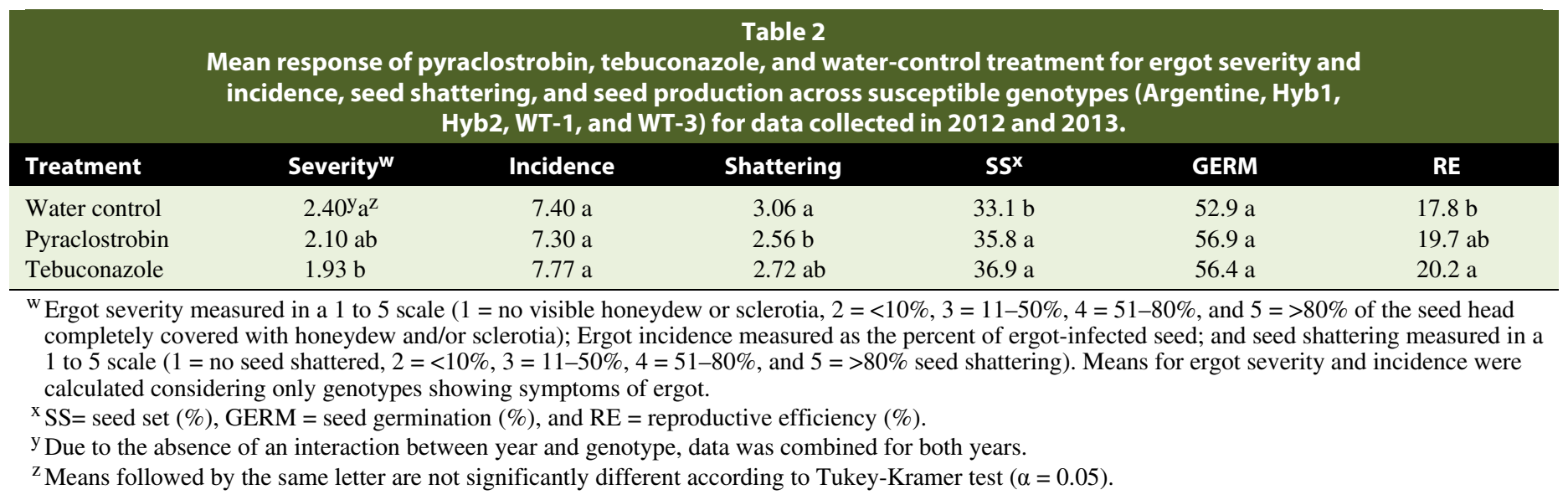


(Table 2). The reduction in ergot severity caused by the application of tebuconazole may not be considered biologically significant, there was approximately $15 \%$ reduction in ergot severity compared to the control, but not differences were found in ergot incidence (Table 2); however, the treatment was applied only once due to heavy rainfall experienced both years, and a second application may have reduced ergot severity and incidence more than only one (Butler et al. 1997; Ryley et al. 2003).

In previous studies, fungicide application significantly reduced sclerotia development when high levels of ergot infection were observed under field conditions (Butler et al. 1997). The level of ergot inoculum present in the field during our experiments in both years might have been too low to detect a significant fungicide effect on ergot incidence in tetraploid bahiagrass. A single application of fungicides at anthesis was not enough to significantly reduce ergot incidence in tetraploid bahiagrass (Table 2), although two applications of fungicides reduced ergot incidence and severity in other crops (Butler et al. 1997; Ryley et al. 2003).

\section{ANTHESIS: THE CRITICAL STAGE FOR ERGOT INFECTION}

Anthesis was the most critical stage in relation to ergot infection in sorghum (Ryley et al. 2003). During sunny, warm, and low-humidity conditions it takes four to six days to complete anthesis in any one raceme in bahiagrass, and in general less than half of the florets on any one raceme opens in a 24-h period (Burton 1942). Seed heads of bahiagrass were collected prior to anthesis, at anthesis, and postanthesis, and were sent to the UF Extension Plant Disease Clinic to confirm ergot presence. Seed heads that had been collected prior to anthesis showed no sign or symptom of ergot infection; however, seed heads collected at anthesis and postanthesis did have ergot symptoms (data not shown). Therefore, application of fungicides prior to anthesis is not likely to be efficacious, especially during cloudy and rainy periods when flowering is delayed (Burton 1942). If chemical control of ergot is attempted in future studies at least two applications should be made, the first fungicide application coinciding with anthesis and the second four to six days afterwards (Butler et al. 1997; Ryley et al. 2003).

\section{HYPOTHESIS ABOUT THE MECHANISM OF RESISTANCE TO ERGOT IN BAHIAGRASS}

Anthesis, pollination, and fertilization in grasses are strongly influenced by environmental conditions, especially rainfall and radiation (Humphreys and Riveros 1986). Cloudy and rainy conditions significantly delayed anthesis in bahiagrass (Burton 1942), so the flowers experienced an extended period of time having the stigmas fresh and receptive, which may be related to greater ergot susceptibility in plants growing under those conditions. It has been reported that diploid genotypes, such as 'Pensacola', are more resistant to ergot compared to tetraploid cultivars (Burton 1955); however, no explanation of the mechanism of resistance has been proposed. Diploid bahiagrass usually set more seed than tetraploid genotypes (Knight and Bennett 1953) and this may be a potential reason for the reduced infection found in diploid genotypes, since ergot infection was negatively correlated to fertility (Burton and Lefebvre 1948). However, Pensacola does not only set more seed than current tetraploid cultivars, but it has smaller florets and seeds than tetraploid genotypes (Gates et al. 2004); therefore, floret size may be another factor influencing ergot susceptibility. The wild-type bahiagrass lines have seeds that are similar in size to Pensacola (Fig. 2); therefore, the hypothesis of smaller flowers and stigmas being exposed during anthesis may be another reason for the reduced ergot infection reported for diploid genotypes, and that may explain the low level of ergot infection found in the wildtype genotypes (Table 1). In addition, Pensacola (Burton 1955) and the wild-type bahiagrass lines (Rios et al. 2013b) can produce recombinant progeny for disease response through sexual reproduction; therefore, they can be utilized to breed for ergot resistant bahiagrass. Contrarily, obligate apomictic bahiagrass [Argentine (Burton 1948) and both hybrids (Acuña et al. 2009)] will not sexually recombine and ergot susceptibility will be passed to progeny unless random natural mutations occur. Nevertheless, further analyses are needed to elucidate the mechanism of resistance to ergot in diploid and tetraploid bahiagrass.

\section{THE EFFECTIVNESS OF TEBUCONAZOLE AND PYRACLOSTROBIN IN SEED SHATTERING}

Seed shattering is a major problem for seed production in Pensacola and dallisgrass (P. dilatatum Poir.) (Burson et al. 1978). Abscission was proposed to occur through the presence of an abscission layer located in the pedicel of the floret, which is distinguishable at the boot stage and fully developed at anthesis (Burson et al. 1978). Seed shattering was visually estimated prior to harvesting using a 1 to 5 scale, with $1=$ no seed shattered, $2=$ $<10 \%, 3=11-50 \%, 4=51-80 \%$, and $5=>80 \%$ seed shattering. Genotype $(P<0.0001)$ had a significant effect on seed shattering. Interestingly, the wild-type lines showed a high level of seed retention up to three weeks after anthesis, which is considered an advantageous characteristic for seed production. However, at three weeks after anthesis Argentine and both hybrids exhibited seed shattering (Table 1), and their seed harvest should not be delayed longer than 3 weeks after peak anthesis due to the potential yield loss. In order to test the efficacy of treatments on seed shattering, the analysis was performed considering only Argentine and both hybrids. Fungicide treatment had a significant effect on seed shattering $(P=0.010)$, and pyraclostrobin significantly reduced seed shattering compared to the control (Table 2). The effect of pyraclostrobin in reducing seed shattering

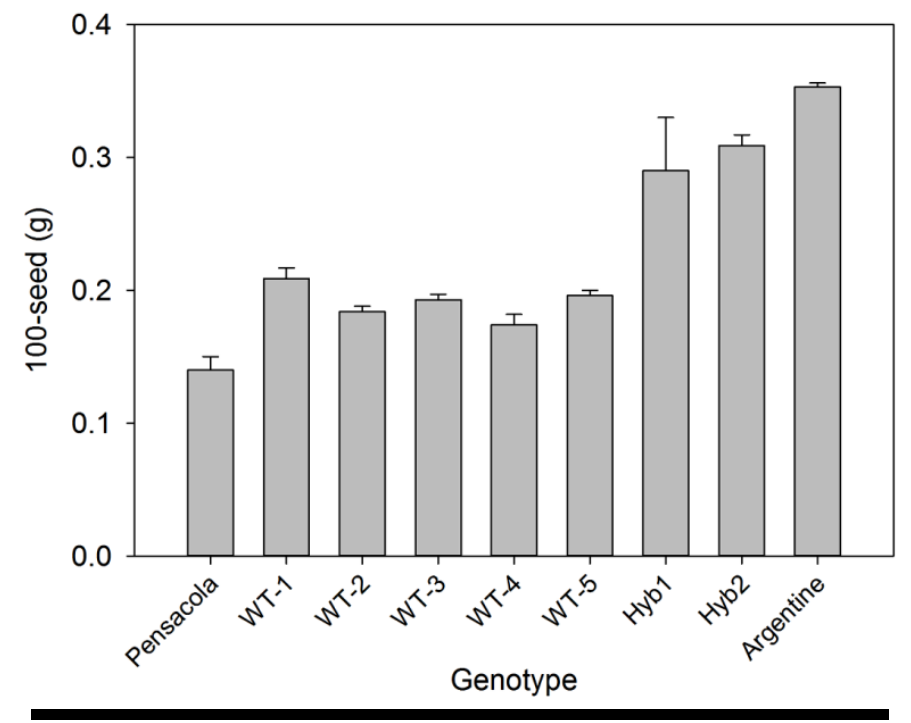

FIGURE 2

Mean weight (g) of 100-seed of 'Pensacola', 'Argentine', and seven bahiagrass breeding lines. Pensacola seed was harvested from a field located in proximity to the experimental area; however, no treatments were applied to this cultivar. Values represent averages and standard deviations from three 100-seed samples. 
is unknown, but it may intensify plant vigor and delay the formation of the abscission layer in the florets.

\section{THE EFFECTIVNESS OF TEBUCONAZOLE AND PYRACLOSTROBIN IN SEED PRODUCTION}

The percent of florets producing seed in warm-season grasses has been suggested to be genetically controlled but susceptible to environmental conditions (Humphreys and Riveros 1986). Genotype $(P<0.0001)$, treatment $(P=0.002)$ and genotype by treatment interaction $(P=0.003)$ significantly affected seed set in this study. There was a great variation in seed set among genotypes (Table 1), and the wild-type lines showed higher seed set values, except for WT-1. Similar seed set was reported in facultative apomictic wild-type bahiagrass under open pollinated conditions (Rebozzio et al. 2011), and in Argentine (Acuña et al. 2007). The apomictic hybrids used in the study exhibited seed set ranging from 14 to $45 \%$ under open pollination (Acuña et al.

2009), and both hybrids in our study had similar values (Table 1). Both fungicides significantly increased seed set compared to the control (Table 2); however, the increment might not be biologically significant. The genotype by treatment interaction arose by the increased seed set observed in the cultivar Argentine caused by tebuconazole, while pyraclostrobin increased seed set on three of the wild-type lines and Hyb2. The relationship between high seed set and ergot resistance previously proposed (Burton and Lefebvre 1948) is not likely to apply to the wild-type and hybrid genotypes in this study. The wild-type genotypes set the same amount of seed compared to Argentine, but their response to ergot was significantly different (Table 1).

Additionally, Hyb1 had higher seed set than Hyb2, but also higher ergot severity, while ergot incidence was similar between both hybrids (Table 1). Therefore, the relationship between high fertility and ergot resistance is not likely simple and linear, and there must be other factors playing an important role in slowing down or impeding the fungus to infect the florets of the wild-type lines, as well as in the diploid germplasm.

Genotype $(P<0.0001)$ and the interaction of genotype by treatment $(P<0.0001)$ had a significant effect on germination. Great variability was found among genotypes for seed germination (Table 1). The obligate apomict cultivar Argentine showed the highest percent germination, while the wild-type genotypes had seed germination lower than $60 \%$ (Table 1). The wild-type lines were classified as facultative apomictic because they have the potential to reproduce by sexual or apomictic means (Rios et al. 2013b), and their low seed germination (Table 1) may be related to the low efficiency of the sexual pathway to produce viable progeny. In the facultative apomictic Paspalum mallacophyllum Trin seed were produced through sexual and apomictic pathways; however, the recovery of sexual progeny was extremely low or zero and exclusively clonal offspring were produced (Hojsgaard et al. 2013). Similarly, very low recombinant progeny was reported in facultative apomictic bahiagrass (Rebozzio et al. 2011) and in facultative apomictic buffelgrass (Cenchrus ciliaris L.) (Sherwood et al. 1980). The significant genotype by treatment interaction arose from the increased seed germination observed for Argentine and WT-3 for the control treatment, while the application of both fungicides increased seed germination in Hyb2, WT-1, WT-4, and WT-5. Using either fungicide, the percent germination increased by $20 \%$ in Hyb2 (the highest increment), when compared to the control treatment. However, because there was not a general trend of higher seed germination after fungicide applications for all genotypes there is not sufficient evidence to recommend fungicide applications to control ergot and enhance seed germination in bahiagrass.

Reproductive efficiency collectively assesses seed set and germination and is a more accurate measurement of the ability of a plant to produce a large number of viable progeny. For reproductive efficiency, genotype $(P<0.0001)$, treatment $(P=0.01)$ and their interaction $(P=0.0002)$ had a significant effect. All experimental lines had lower reproductive efficiency compared to Argentine. The high reproductive efficiency found in Argentine was mainly due to its high seed germination (Table 1). Only three experimental lines Hyb1 (forage-type), WT-3, and WT-5 (turf-types) showed reproductive efficiency larger than $20 \%$ (Table 1), and they would be considered for cultivar release. The single application of tebuconazole increased reproductive efficiency only $2.4 \%$ compared to the control (Table 2), which was statistically significant but it may not be economically acceptable to justify fungicide applications for seed production in bahiagrass. For most of the wild-type lines and Hyb2, tebuconazole produced the highest reproduction efficiency, while for Argentine and Hyb1 it produced the lowest reproductive efficiency, although not statistically different from the other treatments.

\section{SUMMARY AND CONCLUSIONS}

The genotypes used in the study differed markedly in their ergot susceptibility. The cultivar Argentine was confirmed to be susceptible to ergot and showed the highest level of ergot severity and ergot incidence, followed closely by both tetraploid hybrids. In general, the wild-type lines had lower ergot incidence and severity than Argentine, and three of them could be considered resistant to ergot.

Anthesis was confirmed to be the most critical stage in relation to ergot infection in bahiagrass; however, the mechanism of resistance reported in diploid cultivars and observed in the tetraploid wild-type lines needs to be elucidated for efficient selection in a breeding program.

The single application of tebuconazole at anthesis statistically reduced ergot severity; however, the reduction is not considered biologically significant, because ergot incidence was not reduced. As previously reported for other species, a second application after anthesis may be needed to effectively control ergot in susceptible genotypes. Additionally, the application of fungicides did not significantly increase seed quality. Nevertheless, three advanced tetraploid breeding lines produced high quality seed compared to Argentine and would be considered for cultivar release for forage (Hyb1) and turf applications (either WT-3 or WT-5).

\section{AKNOWLEDGMENTS}

This project was funded, in part, from support provided by the University of Florida, Institute of Food and Agricultural Science, Dean for Research. The authors also thank Paul Reith and Brenda Rutherford for technical assistance. 


\section{LITERATURE CITED}

Acuña, C. A., Blount, A. R., Quesenberry, K. H., Hanna W. W., and Kenworthy, K. E. 2007. Reproductive characterization of bahiagrass germplasm. Crop Sci. 47:1711-1717.

Acuña, C. A., Blount, A. R., Quesenberry, K. H., Kenworthy, K. E., and Hanna, W. W. 2009. Bahiagrass tetraploid germplasm: Reproductive and agronomic characterization of segregating progeny. Crop Sci. 49:581-588.

Adjei, M. B., and Mislevy, P. 1987. Bahiagrass seed production as influenced by mechanical, cultural, and chemical treatments. Page 103 in: Agronomy Abstracts. ASA, Madison, WI

Adjei, M. B., Mislevy, P., and Chason, W. 1992. Seed yield of bahiagrass in response to sward management by phenology. Agron. J. 84:599 603 .

Adjei, M. B., Mislevy, P., and Chason, W. 2000. Timing, defoliation management, and nitrogen effects on seed yield of 'Argentine' bahiagrass. Agron. J. 92:36-41.

Alderman, S. C. 2003. Diversity and speciation in Claviceps. Pages 195-245 in: Clavicipitalean Fungi: Evolutionary Biology, Chemistry, Biocontrol, and Cultural Impacts. Marcel Dekker, Inc., New York.

Alderman, S. C., Halse, R. R., and White, J. F. 2004. A reevaluation of the host range and geographical distribution of Claviceps species in the United States. Plant Dis. 88:63-81.

AOSA, Inc. 2012. Rules for testing seeds. Online: www.aosaseed.com

Blount, A. R. S. 2013. Forage Production in the Southern Coastal Plain Region. Pub. SS-AGR-81. University of Florida-IFAS. http://edis.ifas.ufl.edu/aa265.

Blount, A. R., and Acuña, C. A. 2009. Bahiagrass. Pages 81-110 in: Genetic resources, chromosome engineering, and crop improvement series: Forage crops, vol. 5. R. J. Singh, ed. CRC, Boca Raton, FL.

Brown, H. B. 1916. Life history and poisonous properties of Claviceps paspali. J. Agric. Res. 7:401-406.

Burson, B. L., Correa, J., and Potts, H. C. 1978. Anatomical study of seed shattering in bahiagrass and dallisgrass. Crop Sci. 18:122-125.

Burton, G. W. 1942. Observations of the flowering habits of four Paspalum species. Am. J. Bot. 29:179-187.

Burton, G. W. 1948. The method of reproduction in common bahiagrass, Paspalum notatum. J. Am. Soc. Agron. 40:443-452.

Burton, G. W. 1955. Breeding Pensacola bahiagrass, Paspalum notatum: I. method of reproduction. Agron. J. 47:311-314.

Burton, G. W., and Lefebvre, C. L. 1948. Ergot and sterility in bahiagrass. Phytopathology 38:556-559.

Burton, G. W., Gates, R. N., and Gasho, G. J. 1997. Response of Pensacola bahiagrass to rates of nitrogen, phosphorus and potassium fertilizers. Soil Crop Sci. Soc. Florida Proc. 56:31-35.

Butler, M., Alderman, S. N., and Crowe, F. 1997. Evaluation of fungicides for control of ergot in Kentucky bluegrass. Pages 54-56 in: Central Oregon Agricultural Research Center Annual Report 987. COARC, Oregon State University, Corvalis, OR.
Crop Data Management Systems. 2013. www.cdms.net

Feldman, T. S., O'Brien, H., and Arnold, A. E. 2008. Moth dispersal of mycoparasites and endophytes associated with Claviceps paspali and the grass Paspalum (Poaceae). Microb. Ecol. 56:742-750.

Gates, R. N., and Burton, G. W. 1998. Seed yield and seed quality response of Pensacola and improved bahiagrasses to fertilization. Agron. J. 90:607-611.

Gates, R. N., Quarin, C. L., and Pedreira, C. G. S. 2004. Bahiagrass. Pages 651-680 in: Warm-Season (C4) Grasses, L. E. Moser, B. L. Burson, and L. E. Sollenberger, eds. ASA, CSSA, SSSA, Madison, WI.

Hojsgaard, D. H., Martinez, E. J., and Quarin, C.L. 2013. Competition between meiotic and apomictic pathways during ovule and seed development results in clonality. New Phytol. 197:336-347.

Humphreys, L. R., and Riveros, F. 1986. Tropical pasture seed production. Pages 111-121 in: FAO Plant Production and Protection Paper 8. Food and Agriculture Organization of United Nations, Rome.

Jank, L. 1982. Study of factors affecting seed production in 'Pensacola' and 'Argentine' bahiagrass (Paspalum notatum). M.Sc. Thesis. Agronomy Department, University of Florida, Gainesville.

Knight, W. E., and Bennett, H. W. 1953. Preliminary report of the effects of photoperiod and temperature on the flowering and growth of several southern grasses. Agron. J. 45:268-269.

Latin, R. 2011. A Practical Guide to Turfgrass Fungicides (Vol. 1). American Phytopathological Society, St. Paul, MN

Littell, R. C., Miliken, G. A., Stroup, W. W., Wolfinger, R. D., and Schabenberger, O. 2006. SAS for mixed models. 2nd Ed. SAS Institute Inc., Cary, NC.

Newman, Y., Vendramini, J., and Blount, A. 2011. Bahiagrass (Paspalum notatum): Overview and management. Coop. Ext. Serv. Bull. SS-AGR-332. University of Florida, Gainesville. http://edis.ifas.ufl.edu/ag342

Quesenberry, K. H., Dampier, J. M., Lee, Y. Y., Smith, R. L., and Acuña, C. A. 2010. Doubling the chromosome number of bahiagrass via tissue culture. Euphytica. 175:43-50.

Rebozzio, R. N., Sartor, M. E., Quarin, C. L., and Espinoza, F. 2011. Residual sexuality and its seasonal variation in natural apomictic Paspalum notatum accessions. Biol. Plant. 55:391-395.

Rios, E., Blount, A., Erickson, J., Quesenberry, K., Altpeter, F., Cellon, C., and Kenworthy, K. 2013a. Root and shoot characterization of mutant turf-type bahiagrass. Int. Turfgrass Soc. Res. J. 12:509-516.

Rios, E., Blount, A., Kenworthy, K., Acuña, C., and Quesenberry, K. 2013b. Seasonal expression of apospory in bahiagrass. Tropical GrasslandsForrajes Tropicales 1:116-118.

Ryley, M., Bhuiyan, S., Herde, D., and Gordan, B. 2003. Efficacy, timing and method of application of fungicides for management of sorghum ergot caused by Claviceps africana. Australas. Plant Pathol. 32:329-338.

Sherwood, R. T., Young, B. A., and Bashaw, E. C. 1980. Facultative apomixis in Cenchrus ciliaris. Crop Sci. 20:375-379.

Villar, A. D. 1984. Pasto miel: aportes para su introducción en nuestras praderas consociadas. Acintacnia 5:34-35. 